\title{
Comparative analysis of rotor losses in high-speed permanent magnet machines with different winding configurations considering the influence of the inverter PWM
}

\author{
Citation for published version (APA): \\ Merdzan, M., Paulides, J. J. H., \& Lomonova, E. A. (2015). Comparative analysis of rotor losses in high-speed \\ permanent magnet machines with different winding configurations considering the influence of the inverter PWM. \\ In Proceedings of the 10th IEEE International Conference on Ecological Vehicles and Renewable Energies \\ (EVER 2015), March 31 - April 2, 2015, Monaco (pp. 1-8). Institute of Electrical and Electronics Engineers.
}

\section{Document status and date:}

Published: 01/01/2015

\section{Document Version:}

Publisher's PDF, also known as Version of Record (includes final page, issue and volume numbers)

\section{Please check the document version of this publication:}

- A submitted manuscript is the version of the article upon submission and before peer-review. There can be important differences between the submitted version and the official published version of record. People interested in the research are advised to contact the author for the final version of the publication, or visit the $\mathrm{DOI}$ to the publisher's website.

- The final author version and the galley proof are versions of the publication after peer review.

- The final published version features the final layout of the paper including the volume, issue and page numbers.

Link to publication

\footnotetext{
General rights

- You may freely distribute the URL identifying the publication in the public portal. follow below link for the End User Agreement:

www.tue.nl/taverne

\section{Take down policy}

If you believe that this document breaches copyright please contact us at:

openaccess@tue.nl

providing details and we will investigate your claim.
}

Copyright and moral rights for the publications made accessible in the public portal are retained by the authors and/or other copyright owners and it is a condition of accessing publications that users recognise and abide by the legal requirements associated with these rights.

- Users may download and print one copy of any publication from the public portal for the purpose of private study or research.

- You may not further distribute the material or use it for any profit-making activity or commercial gain

If the publication is distributed under the terms of Article $25 \mathrm{fa}$ of the Dutch Copyright Act, indicated by the "Taverne" license above, please 


\title{
Comparative Analysis of Rotor Losses in High-Speed Permanent Magnet Machines with Different Winding Configurations Considering the Influence of the Inverter PWM
}

\author{
M. Merdzan, J. J. H. Paulides and E. A. Lomonova \\ Department of Electrical Engineering \\ Eindhoven University of Technology \\ Den Dolech 2, 5612 AZ, Eindhoven, The Netherlands
}

E-mail: M.Merdzan@tue.nl

\begin{abstract}
Due to development in fields of materials and power electronics, use of high-speed electrical machines has boosted significantly in recent decades. They are widely used in number of applications, such as electrically assisted turbochargers, flywheel energy storage systems, spindle applications, turbo molecular pumps, micro gas turbines. In applications where high efficiency and high power density are required, the most suitable machine type for high-speed operations is a permanent magnet (PM) machine. In this paper the performance of several different topologies of high-speed PM machines required for use in a micro-gas turbine application are evaluated. Different winding topologies, retaining sleeve materials and magnetization patterns are considered, where the main criterion for the machine performance are eddy current losses in the rotor. Influence of time harmonics in stator currents caused by the inverter Pulse Width Modulation (PWM) is incorporated in the calculation.

Index Terms-High-speed machines, permanent magnets, eddy current losses, retaining sleeve, windings, magnetization
\end{abstract}

\section{INTRODUCTION}

For use in high-speed applications, 3 types of electrical machines are most widely used: induction machines, switched reluctance machines and permanent magnet (PM) machines [1], [2], [3]. High-speed induction machines can be found in electrically assisted turbochargers [4], centrifugal compressors [5], turbo molecular pumps [6], [7]. Rotor design of high-speed induction machines, which often incorporates solid structure, is quite robust which makes this machine type very suitable for high mechanical stresses accompanying high-speed rotation. However, rotor currents in induction machines create

978-1-4673-6785-1/15/\$31.00 (c) 2015 European Union an additional loss component which does not exist in switched reluctance and PM machines. This makes them less favorable for applications where the efficiency is of high priority.

Switched reluctance machines are a good candidate for high-speed operation, due to absence of both current carrying regions and permanent magnets on the rotor. They can be found in vacuum cleaners, air blowers and similar devices where low price is one of the most important criteria [8], [9]. Ability of this machine type to operate under faulted conditions, in tough environment with very high temperatures puts them in use in aircraft gas turbine applications [10], [11]. However, they also require magnetization currents which deteriorates their efficiency and power factor. Furthermore, due to a structure which incorporates double saliency, windage losses tend to become high in this machine type, especially at high speeds [12]. Although it is possible to overcome this by potting rotor and stator slots, it would make production process more complicated and expensive.

In contrast to previously mentioned machine types, PM machines do not require either rotor or excitation currents, which makes them a priori preferable from the efficiency point of view. Furthermore, because of the utilization of high energy sintered $\mathrm{NeFeB}$ and $\mathrm{SmCo}$ magnets, PM machines are able to produce significant output power despite the low volume typical for highspeed operation [13], [14]. Therefore, high-speed PM machines are widely used in power generating applications [15], [16], as well as in many others [1], [17], [18].

A significant disadvantage of use of PM machines are thermal and mechanical vulnerability of permanent magnet materials. Because of inability of sintered $\mathrm{NeFeB}$ and SmCo magnets to withstand rotationally induced tensile 
stresses, they are often contained in retaining sleeves [3], [13]. The sleeves expose magnets to compression, which sintered $\mathrm{NeFeB}$ and $\mathrm{SmCo}$ can handle. If made of conducting materials, retaining sleeves are prone to eddy currents and therefore Joule losses. The existence of a conducting layer around the magnets can either increase or decrease [19] total rotor losses, depending on several factors. However, rotor losses always heat up the magnets.

With temperature increase both remanent flux density and coercivity of the magnets decrease, deteriorating their ability to produce sufficient magnetic flux and increasing demagnetization risk [20]. In order to ensure stabile operation of high-speed PM machines rotor temperature (and therefore eddy current losses in the rotor) have to be kept as low as possible.

Rotor eddy currents in PM machines are caused by the flux density harmonics rotating asynchronously with respect to the rotor. This asynchronism originates from the spatial harmonics in stator MMF distribution [21] and time harmonics in stator currents as a consequence of PWM [22]. Therefore, stator configuration has a significant impact on the rotor losses and this has to be kept in mind during the high-speed PM machine design.

In this paper the influence of different stator winding configurations on rotor losses of high-speed PM machines is analyzed. The analysis includes the effect of PWM which in high-speed machines can be significant. Beside that, effect of use of several different retaining sleeve materials, as well as two different magnetization patterns on the rotor are examined. For all analyzed cases rotor losses are compared for the same generated electromagnetic torque.

\section{WINDING TOPOLOGIES AND RETAINING SLEEVE MATERIALS IN HIGH-SPEED PM MACHINES}

In this section, winding topologies and retaining sleeve materials most widely used in high-speed PM machines will be briefly discussed with emphasis on their advantages and disadvantages.

\section{A. Winding topologies}

Winding topology is a very important factor for performance of high-speed PM machines. Beside determining electrical loading, copper losses and inductance, it also significantly influences rotor losses. Additionally, the winding topology determines production costs, based on the fact whether a given winding can be produced automatically or the manual labor is required.

Winding topologies can generally be classified into overlapping and non-overlapping [23]. Overlapping windings, sometimes referred to as distributed, are made with the winding pitch equal or slightly shorter than the pole pitch, having relatively high winding factor. A disadvantage of this winding type is the existence of relatively long end windings, which increase copper consumption and Joule losses. Additionally, long end windings require increase of the axial length of the machine, which in some high-speed machines can be even twice the length of the stack [24]. In order to reduce the amount of copper and improve harmonic performance, coils in this windings are often short-pitched [25]. Additionally, for the reduction of the harmonic content of the stator MMF conductors are often distributed in several adjacent slots, if sufficient number of slots is available. However, both these measures reduce the fundamental winding factor.

Non-overlapping windings, sometimes referred to as tooth-coil [26] or concentrated, are usually made by putting conductors around a single stator tooth [3], [24], [17]. This makes the end windings short and enables simple manufacturing process. However, the winding factor decreases due to the significant short pitching. This requires higher number of turns or increase in the stack length to generate the same torque as an equivalent overlapping winding. To illustrate significance of the winding topology selection, two overlapping and two non-overlapping winding topologies will be compared in this paper from the rotor losses point of view.

\section{B. Retaining sleeve materials}

Retaining sleeves convert stress in magnets from tensile to compressive. Since stress in the sleeves due to the connection with magnets and due to rotation act in the same direction, adding up [27], materials with high tensile strength have to be used. In the existing applications different metallic materials such as titanium [13], stainless steel [3], and Inconel [28] can be found. In many high-speed applications metallic sleeves are used for the torque transfer to the shaft, since high-speed PM rotors are often made with solid PM cylinders without the inner shaft in order to avoid high values of stress appearing at inner bore of hollow magnet cylinders [29].

While considering rotor losses, an important criterion in design of the retaining sleeve is its electrical conductivity. Namely, the penetration depth in a material exposed to time changing magnetic field is expressed as:

$$
\delta=\sqrt{\frac{2}{\omega \mu \sigma}}
$$

In (1) $\omega$ is the angular frequency of the magnetic field, $\mu$ is the permeability and $\sigma$ is the electric conductivity of the material. It can be seen that by changing the conductivity (and permeability) of the sleeve, field distribution in the rotor can be affected, as well as distribution 
of induced eddy currents. Consequently, eddy currents losses can mostly be present in the sleeve, in the case of very high sleeve conductivity, or in both the sleeve and the magnet, in the case of lower sleeve conductivity.

If a material with lower electric conductivity is used for the sleeve, eddy currents will have higher chance to reach the magnet. Since materials with low electrical conductivity are usually bad heat conductors, the magnet cooling through the sleeve will be difficult in this case. Conversely, if a sleeve material with a higher conductivity is used, eddy currents will be mostly located in the sleeve itself. Due to the direct contact with the air gap, cooling of the sleeve is much easier. Therefore, from the point of view of cooling, sleeve with higher conductivity seems like better choice. The influence of the sleeve conductivity on the amount of rotor losses will be further investigated in this paper.

\section{ROTOR LOSSES IN HIGH-SPEED PM MACHINES WITH DIFFERENT WINDING TOPOLOGIES AND RETAINING SLEEVE MATERIALS}

In this section, a comparison of several PM machines with different winding topologies and retaining sleeve materials from the rotor losses point of view is done. All machines have two poles and utilize a dipole (diametrical) magnetization [30] on the rotor. In total, four different winding topologies and three different retaining sleeve materials are analyzed. Considered winding topologies are shown in Fig. 1, where two of them utilize non-overlapping windings and two utilize overlapping windings. Orange color indicates a $\mathrm{NeFeB}$ magnet with remanent flux density of $1.19 \mathrm{~T}$ and coercivity of 899 $\mathrm{kA} / \mathrm{m}$, while the retaining sleeve is indicated in turquoise. Coils belonging to three phases are indicated in red, blue and green, together with the corresponding coils orientation.

Topology T1, analyzed in, for instance [3] and [18], utilizes a stator with three slots. It is quite simple and relatively easy for production. Topology $\mathrm{T} 2$, used in [26] and [17], is another topology with non-overlapping windings which utilizes double layer winding pattern with two coils per phase. Because of very short coil pitch it has the lowest winding factor out of all four considered topologies. Topology T3 uses a full pitch overlapping winding with six slots. Beside use of this winding pattern in slotless PM machines in so called toroidal structure [29], [31]; it is also suggested for use in slotted machines [32]. Eventually, topology T4 utilizes 12 slot overlapping winding. Because of higher number of slots and use of double layer structure both short pitching and distribution of conductors in adjacent slots are possible for getting the optimal harmonic performance.
Additionally, electrical conductivity of three considered retaining sleeve materials are displayed in Table I.

Physical dimensions of all four considered machines

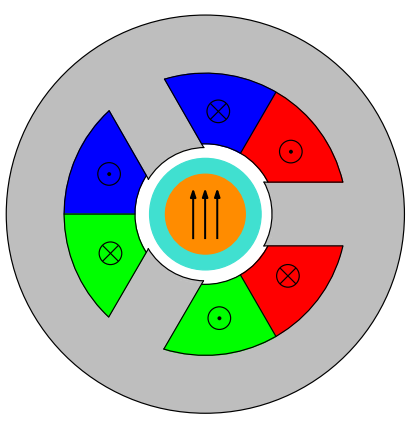

(a) $\mathrm{T} 1$

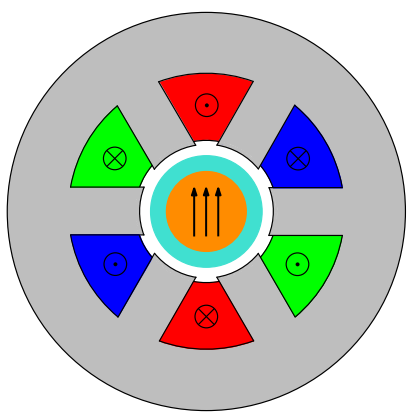

(c) $\mathrm{T} 3$

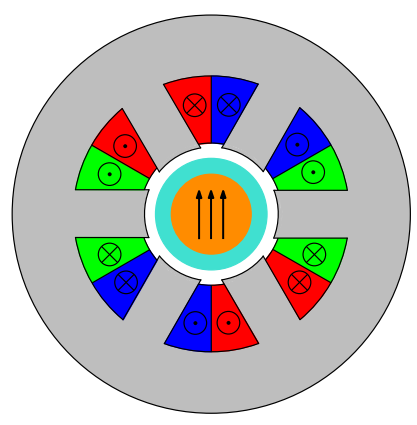

(b) $\mathrm{T} 2$

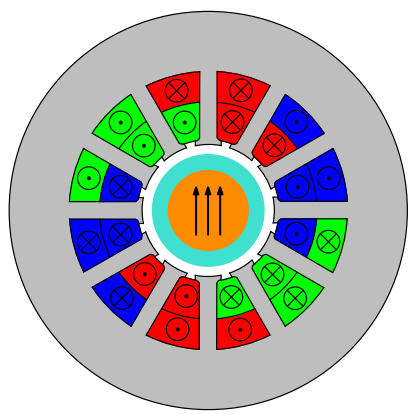

(d) $\mathrm{T} 4$
Fig. 1. Considered winding topologies

TABLE I

ELECTRICAL CONDUCTIVITY OF DIFFERENT MATERIALS USED IN ROTORS OF CONSIDERED HIGH-SPEED PM MACHINES

\begin{tabular}{cc}
\hline \hline Material & Electrical conductivity $[\mathrm{S} / \mathrm{m}]$ \\
\hline \hline Inconel 718 & $0.83 \cdot 10^{6}$ \\
\hline Stainless steel & $1.45 \cdot 10^{6}$ \\
\hline Titanium & $2.38 \cdot 10^{6}$ \\
\hline
\end{tabular}

are kept same. The number of stator turns is selected so that all four machines generate a torque corresponding to $3.7 \mathrm{~kW}$ of output power at the rotational speed of 240.000 rpm for a high-speed PM generator driven by a micro-gas turbine [28]. To get an impression about difference in number of turns, the fundamental winding factor for all four machines is shown in Table II.

As a main indicator of the machines' performance,

TABLE II

FUNDAMENTAL WINDING FACTOR FOR MACHINES SHOWN IN FIG. 1

\begin{tabular}{ccccc}
\hline \hline Winding factor & T1 & T2 & T3 & T4 \\
\hline \hline$k_{W}$ & 0.866 & 0.5 & 1 & 0.944 \\
\hline
\end{tabular}


rotor losses are considered, due to their significance in PM machines and potential risk of magnet demagnetization caused by them. The analysis is done by means of the harmonic modeling approach [33], [34] and verified by $2 \mathrm{D}$ transient finite element analysis.

In order to illustrate the difference between four considered topologies, Table III shows relative amplitudes (with respect to the fundamental) of first 13 harmonics in winding spatial distribution. Spatial harmonics which are multiple of three are not listed in the table since they do not create a net stator field [28]. From Table III it can be seen that structure used in topology $\mathrm{T} 2$ contains both even and odd harmonics in spatial winding distribution, in contrast to other three topologies, which suggests that high rotor losses might be expected. Topologies 2 and 3 have same relative values of spatial harmonics; however, topology $\mathrm{T} 2$ requires twice the number of turns of topology T3 to generate the same torque.

Since high-speed PM machines are usually inverter-

TABLE III

RELATIVE VALUES OF SPATIAL HARMONICS IN WINDING DISTRIBUTION OF THE CONSIDERED TOPOLOGIES

\begin{tabular}{ccccc}
\hline \hline Harmonic order & T1 & T2 & T3 & T4 \\
\hline \hline 2 & 0.94 & 0 & 0 & 0 \\
\hline 4 & 0.71 & 0 & 0 & 0 \\
\hline 5 & 0.56 & 0.93 & 0.93 & 0.07 \\
\hline 7 & 0.24 & 0.86 & 0.86 & 0.07 \\
\hline 8 & 0.10 & 0 & 0 & 0 \\
\hline 10 & 0.12 & 0 & 0 & 0 \\
\hline 11 & 0.19 & 0.68 & 0.68 & 0.91 \\
\hline 13 & 0.22 & 0.57 & 0.57 & 0.88 \\
\hline
\end{tabular}

fed, in order to get realistic prediction of rotor losses, influence of the inverter has to be taken into account. Time harmonics in stator currents cause spatial harmonics of air gap flux density to rotate faster with respect to the rotor, introducing new components of rotor eddy current losses.

In this analysis, the same stator current waveform is assumed for all four considered machines. The current waveform, obtained from the existing high-speed PM machine (winding topology T4) running continuously with fundamental component of current of 12 A RMS at $4 \mathrm{kHz}$ is shown in Fig. 2. Time harmonics due to PWM are clearly visible. Calculation of rotor losses caused by PWM harmonics is done using the method presented in [28].

Results of rotor loss calculation for all four machines, considering different sleeve materials and current harmonics introduced by PWM are shown in Table IV.

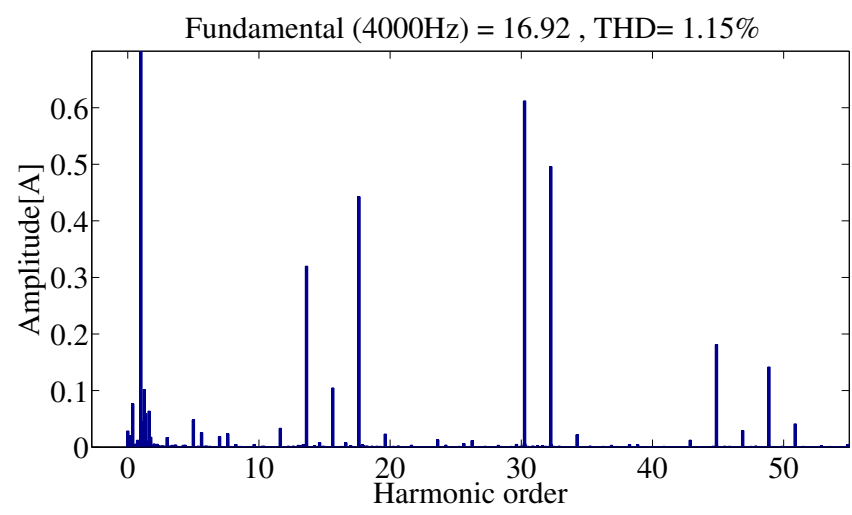

Fig. 2. The current waveform used for calculation of rotor loses

Results are shown separately for losses caused by fundamental current harmonic and all harmonics from Fig. 2. It can be seen that topology $\mathrm{T} 1$, which utilizes three slot stator suffers from significant rotor losses, which are mainly caused by the fundamental component of the stator current. Such large losses would result in a significant rotor temperate increase and probably lead to the magnet demagnetization.

It is interesting to note that topologies 2 and 3, although having different winding distribution and number of turns, have the same rotor losses which are significantly lower than in the case of topology $\mathrm{T} 1$. These losses are mainly caused by the fundamental component of stator current, however, losses generated by PWM harmonics take higher portion of overall losses in comparison to topology $\mathrm{T} 1$.

The most favorable out of four considered topologies from the point of view of rotor losses is topology $\mathrm{T} 4$, with total rotor losses lower than $10 \mathrm{~W}$ for all considered retaining sleeve materials. These losses are mainly caused by PWM harmonics. Such a low value is a result of two factors: distribution of conductors in adjacent slots and appropriate short pitching, which significantly reduces fifth and seventh spatial harmonic. Both factors are enabled by the existence of a higher number of slots. The other three topologies, although simpler for production, are not flexible in the winding design because of limited options for conductor placement due to lower number of slots.

Based on results in Table IV it can be discussed how rotor losses in considered machines change with different sleeve materials. It can be seen that for topologies 1 , 2 and 3, where rotor losses are mainly caused by the fundamental time harmonic of the current, total rotor losses increase with the increase of sleeve conductivity. In contrast, for topology $\mathrm{T} 4$, total rotor losses decrease with the increase of the sleeve conductivity.

This effect is explained by the nature of rotor eddy 
TABLE IV

COMPARISON OF ROTOR LOSSES IN MACHINES WITH DIFFERENT WINDING TOPOLOGIES (IN WATTS)

\begin{tabular}{|c|c|c|c|}
\hline Sleeve material & Inconel 718 & Stainless steel & Titanium \\
\hline \hline \multicolumn{5}{|c|}{ Topology T1 } \\
\hline Fundamental & 173.5 & 248.6 & 303.3 \\
\hline All harmonics & 188.6 & 260.4 & 312.8 \\
\hline \multicolumn{4}{|c|}{ Topology T2 } \\
\hline Fundamental & 22.4 & 37.5 & 56.9 \\
\hline All harmonics & 31.8 & 44.9 & 63.0 \\
\hline \multicolumn{5}{|c|}{ Topology T3 } \\
\hline Fundamental & 22.4 & 37.5 & 56.9 \\
\hline All harmonics & 31.8 & 44.9 & 63.0 \\
\hline \multicolumn{5}{|c|}{ Topology T4 } \\
\hline Fundamental & 1.2 & 2.1 & 3.3 \\
\hline All harmonics & 9.2 & 8.0 & 7.9 \\
\hline
\end{tabular}

currents at the considered frequencies [35]. Eddy currents caused by the low frequency magnetic field due to the fundamental time harmonic of the current are socalled resistance limited eddy currents and losses caused by them increase with the material conductivity. On other hand, rotor eddy currents resulting from high-frequency PWM components of current are so-called inductance limited eddy currents and losses caused by them increase with the increase of material resistivity.

\section{PeRformance OF HIGH-SPEED PM MACHINES WITH DIFFERENT ROTOR MAGNETIZATION PATTERNS}

Based on results obtained in the previous section, winding topology $\mathrm{T} 4$ is the most prominent among considered topologies and only this topology will therefore be a subject of further analysis in this chapter.

An additional degree of freedom in a design of highspeed PM machines is the magnetization pattern on the rotor. Although dipole magnetization on the rotor is most widely used in high-speed applications [3], [13], in this section it will be examined how radial magnetization on the rotor influences the machine performance. In Fig. 3 two considered magnetization patterns are shown: dipole (diametrical) and radial magnetization, together with spatial distribution of the radial component of the magnetization $M_{r}(\varphi)$ corresponding to each of them, where $\varphi$ represents the angular coordinate in the rotor reference frame. For diametrically magnetized magnet, the radial component of the magnetization is sinusoidally distributed around the rotor circumference [36]. Both machines have same dimensions and same stator winding, corresponding to topology $\mathrm{T} 4$ form the previous section. Furthermore, the remanent flux density of both magnets has the same value of $1.19 \mathrm{~T}$ like in the previous section (which corresponds to magnetization $M_{0}$ in Fig. 3) with coercivity of $899 \mathrm{kA} / \mathrm{m}$.

Magnetic field of the magnet in the considered

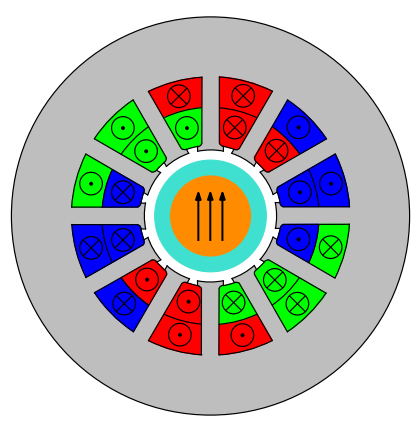

(a) Dipole magnetization

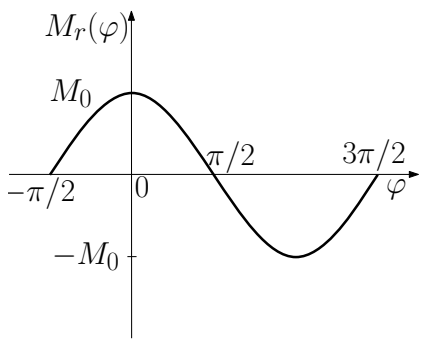

(c) Spatial distribution of the radial component of magnetization

Fig. 3. Different magnetization patterns on the rotor of topology 4 and spatial distribution of radial component of magnetization

machines is solved by means of harmonic modeling approach [37], and in Fig. 4 radial flux density at the surface of the retaining sleeve is shown. It can be seen that in the case of radially magnetized magnet, flux density waveform contains harmonics as a consequence of the magnetization pattern. At the same time, the amplitude of the flux density waveform is significantly lower in comparison to one with dipole magnetization.

In Fig. 5 waveforms of induced electromotive force

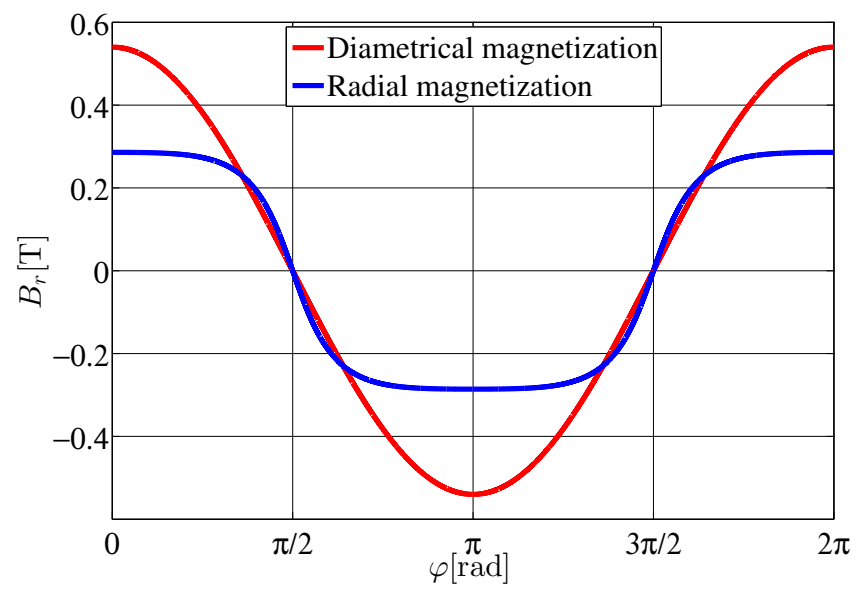

Fig. 4. Radial flux density at the sleeve surface for machines shown in Fig. 3

in machines from Fig. 3 are displayed, considering the number of turns determined in the previous section for topology $\mathrm{T} 4$. The induced voltage in the machine 
with radially magnetized magnet has more than 1.5 times lower amplitude of the fundamental component in comparison to the machine with diametrically magnetized magnet, resulting in lower torque generation for the same electrical loading. Furthermore, a significant amount of third harmonic is present, in order of $10 \%$ of the fundamental component. Nevertheless, this does not influence the machine performance since the current which would be a consequence of third harmonic in EMF cannot flow in a three phase winding in $\mathrm{Y}$ connection [38].

In order to generate the same torque in the ma-

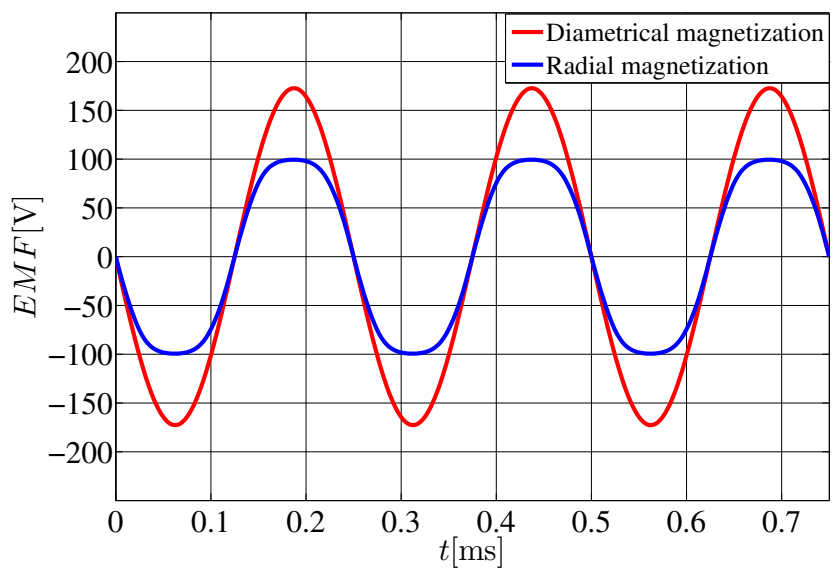

Fig. 5. Waveforms of induced EMFs in machines shown in Fig. 3

chine with radially magnetized magnet, it is necessary to increase the number of turns proportionally to the decrease of the fundamental component of induced EMF. After increasing the number of turns, rotor losses for the machine with radial magnetization are calculated again assuming current harmonic content shown in Fig. 2. Results are shown in Table V. It can be seen that, as expected, rotor losses have increased more than twice in comparison to results for topology $\mathrm{T} 4$ shown in Table IV. Having in mind that an increase in the number of turns also increases copper losses proportionally to the number of added turns, it can be concluded that radially magnetized magnets are definitely inferior for use in high-speed PM machines in comparison to diametrically magnetized ones.

TABLE V

ROTOR LOSSES IN THE MACHINE WITH RADIALLY MAGNETIZED MAGNET (IN WATTS)

\begin{tabular}{|c|c|c|c|}
\hline Sleeve material & Inconel 718 & Stainless steel & Titanium \\
\hline \hline \multicolumn{4}{|c|}{ T4 with radial magnetization } \\
\hline Fundamental & 2.9 & 5 & 8 \\
\hline All harmonics & 22.3 & 16.5 & 19.1 \\
\hline
\end{tabular}

\section{Conclusions}

In this paper, analysis of rotor eddy current losses in high-speed high power dense permanent magnet machines has been performed. Rotor losses have been compared for machines with several winding topologies, retaining sleeve materials and magnetization patterns, where number of turns has been selected in a way that all selected topologies result in a same electromagnetic torque.

From the obtained results it can be concluded that three-slot non-overlapping winding topology which is widely used in other high-speed applications is not convenient for use in high power density applications because of significant rotor losses which would probably overheat the magnet and lead to its demagnetization. These losses are in range between $5 \%$ and $8 \%$ of the target output power for different analyzed retaining sleeve materials.

Considered overlapping and non-overlapping topologies which employ six slots generate equal amount of rotor losses, which are in best case lower than $1 \%$ of the target output power if the retaining sleeve is made of Inconel 718 alloy. In order to assess demagnetization risk for these two topologies, a thermal model of the considered machines should be developed.

By far the most suitable winding topology for minimization of rotor losses is the one which utilizes double layer short pitched overlapping winding and twelve stator slots. Rotor losses for all analyzed retaining sleeve materials are below $10 \mathrm{~W}$.

For all considered topologies, rotor losses caused by the inverter PWM harmonics could be suppressed by using the retaining sleeve material with higher electric conductivity. However, this would lead to the increase of the losses caused by the fundamental component of the current. Therefore, for further minimization of rotor losses this measure should be considered only for topology T4, where PWM caused rotor losses are dominant.

Eventually, by comparing radial and dipole magnetization for the latter mentioned winding topology, it has been shown that the use of dipole magnetization is preferred because of its increased magnetic loading. For the same generated torque the machine with radially magnetized magnet would suffer from more than two times higher rotor losses as a result of required increase in the number of stator turns.

\section{ACKNOWLEDGMENT}

The authors would like to thank Micro Turbine Technology BV for cooperation on the development of a high 
speed generator for micro-CHP, as well as KIC InnoEnergy for providing research and development funds.

\section{REFERENCES}

[1] D. Gerada, A. Mebarki, N. Brown, C. Gerada, A. Cavagnino, and A. Boglietti, "High-speed electrical machines: Technologies, trends, and developments," Industrial Electronics, IEEE Transactions on, vol. 61, no. 6, pp. 2946-2959, June 2014.

[2] A. Tenconi, S. Vaschetto, and A. Vigliani, "Electrical machines for high-speed applications: Design considerations and tradeoffs," Industrial Electronics, IEEE Transactions on, vol. 61, no. 6, pp. 3022-3029, June 2014.

[3] N. Bianchi, S. Bolognani, and F. Luise, "Potentials and limits of high-speed pm motors," Industry Applications, IEEE Transactions on, vol. 40, no. 6, pp. 1570-1578, Nov 2004.

[4] D. Gerada, A. Mebarki, N. Brown, K. Bradley, and C. Gerada, "Design aspects of high-speed high-power-density laminatedrotor induction machines," Industrial Electronics, IEEE Transactions on, vol. 58, no. 9, pp. 4039-4047, Sept 2011.

[5] W. Soong, G. Kliman, R. Johnson, R. White, and J. Miller, "Novel high-speed induction motor for a commercial centrifugal compressor," Industry Applications, IEEE Transactions on, vol. 36, no. 3, pp. 706-713, May 2000.

[6] A. Boglietti, R. Bojoi, A. Cavagnino, P. Guglielmi, and A. Miotto, "Analysis and modeling of rotor slot enclosure effects in high-speed induction motors," Industry Applications, IEEE Transactions on, vol. 48, no. 4, pp. 1279-1287, July 2012.

[7] O. Bottauscio, F. Casaro, M. Chiampi, S. Giors, C. Maccarrone, and M. Zucca, "High-speed drag-cup induction motors for turbo-molecular pump applications," Magnetics, IEEE Transactions on, vol. 42, no. 10, pp. 3449-3451, Oct 2006.

[8] J. Kim and R. Krishnan, "High efficiency single-pulse controlled switched reluctance motor drive for high speed $(48 \mathrm{k}$ rpm) application: Analysis, design, and experimental verification," in Industry Applications Society Annual Meeting, 2008. IAS '08. IEEE, Oct 2008, pp. 1-8.

[9] D.-H. Lee, T. H. Pham, and J.-W. Ahn, "Design and operation characteristics of four-two pole high-speed srm for torque ripple reduction," Industrial Electronics, IEEE Transactions on, vol. 60, no. 9, pp. 3637-3643, Sept 2013.

[10] C. Ferreira, S. Jones, W. Heglund, and W. Jones, "Detailed design of a 30-kw switched reluctance starter/generator system for a gas turbine engine application," Industry Applications, IEEE Transactions on, vol. 31, no. 3, pp. 553-561, May 1995.

[11] R. Hall, A. Jack, B. Mecrow, and A. Mitcham, "Design and initial testing of an outer rotating segmented rotor switched reluctance machine for an aero-engine shaft-line-embedded starter/generator," in Electric Machines and Drives, 2005 IEEE International Conference on, May 2005, pp. 1870-1877.

[12] M. Mekhiche, J. Kirtley, M. Tolikas, E. Ognibene, J. Kiley, E. Holmansky, and F. Nimblett, "High speed motor drive development for industrial applications," in Electric Machines and Drives, 1999. International Conference IEMD '99, May 1999, pp. 244-248.

[13] C. Zwyssig, M. Duerr, D. Hassler, and J. Kolar, "An ultra-highspeed, $500000 \mathrm{rpm}, 1 \mathrm{kw}$ electrical drive system," in Power Conversion Conference - Nagoya, 2007. PCC '07, April 2007, pp. $1577-1583$.

[14] J. Oyama, T. Higuchi, T. Abe, K. Shigematsu, and R. Moriguchi, "The development of small size ultra-high speed drive system," in Power Conversion Conference - Nagoya, 2007. PCC '07, April 2007, pp. 1571-1576.

[15] C. Zwyssig, J. Kolar, W. Thaler, and M. Vohrer, "Design of a $100 \mathrm{w}, 500000 \mathrm{rpm}$ permanent-magnet generator for mesoscale gas turbines," in Industry Applications Conference,
2005. Fourtieth IAS Annual Meeting. Conference Record of the 2005, vol. 1, Oct 2005, pp. 253-260 Vol. 1.

[16] J. Danilevich, I. Kruchinina, V. Antipov, Y. Khozikov, and A. Ivanova, "Some problems of the high-speed permanent magnet miniturbogenerators development," in Electrical Machines, 2008. ICEM 2008. 18th International Conference on, Sept 2008, pp. $1-4$.

[17] T. Noguchi and M. Kano, "Development of $150000 \mathrm{r} / \mathrm{min}, 1.5$ kw permanent-magnet motor for automotive supercharger,' in Power Electronics and Drive Systems, 2007. PEDS '07. 7th International Conference on, Nov 2007, pp. 183-188.

[18] Z. Zhu, K. Ng, and D. Howe, "Design and analysis of highspeed brushless permanent magnet motors," in Electrical Machines and Drives, 1997 Eighth International Conference on (Conf. Publ. No. 444), Sep 1997, pp. 381-385.

[19] J. van der Veen, L. Offringa, and A. Vandenput, "Minimising rotor losses in high-speed high-power permanent magnet synchronous generators with rectifier load," Electric Power Applications, IEE Proceedings -, vol. 144, no. 5, pp. 331-337, Sep 1997.

[20] D. Dorrell, M. Hsieh, M. Popescu, L. Evans, D. Staton, and V. Grout, "A review of the design issues and techniques for radial-flux brushless surface and internal rare-earth permanentmagnet motors," Industrial Electronics, IEEE Transactions on, vol. 58, no. 9, pp. 3741-3757, Sept 2011.

[21] K. Atallah, D. Howe, P. Mellor, and D. Stone, "Rotor loss in permanent-magnet brushless ac machines," Industry Applications, IEEE Transactions on, vol. 36, no. 6, pp. 1612-1618, Nov 2000.

[22] F. Deng, "Commutation-caused eddy-current losses in permanent-magnet brushless dc motors," Magnetics, IEEE Transactions on, vol. 33, no. 5, pp. 4310-4318, Sep 1997.

[23] A. EL-Refaie, "Fractional-slot concentrated-windings synchronous permanent magnet machines: Opportunities and challenges," Industrial Electronics, IEEE Transactions on, vol. 57, no. 1, pp. 107-121, Jan 2010.

[24] N. Bianchi, S. Bolognani, and F. Luise, "High speed drive using a slotless pm motor," Power Electronics, IEEE Transactions on, vol. 21, no. 4, pp. 1083-1090, July 2006.

[25] V. H. Juha Pyrhonen, Tapani Jokinen, Design of rotating electrical machines. John Wiley \& Sons, Ltd, 2007.

[26] N. Uzhegov, J. Nerg, and J. Pyrhonen, "Design of 6-slot 2pole high-speed permanent magnet synchronous machines with tooth-coil windings," in Electrical Machines (ICEM), 2014 International Conference on, Sept 2014, pp. 2537-2542.

[27] R. Larsonneur, "Design and control of active mamagnet bearing systems for high speed rotation," Ph.D. dissertation, Swiss Federal Institute of Technology Zurich, 1990.

[28] M. Merdzan, A. Borisavljevic, and E. Lomonova, "Modeling the influence of commutation in voltage source inverters on rotor losses of permanent magnet machines," in Power Electronics and Applications (EPE'14-ECCE Europe), 2014 16th European Conference on, Aug 2014, pp. 1-10.

[29] A. Borisavljevic, "Limits, modeling and design of high-speed permanent magnet machines," Ph.D. dissertation, Delft University of Technology, 2011.

[30] J. Paulides, E. Lomonova, A. Vandenput, and E. Zaaijer, "Sinusoidal behavior of a dipole magnetization for position sensing applications," Magnetics, IEEE Transactions on, vol. 42, no. 10, pp. 3294-3296, Oct 2006.

[31] S. Jumayev, A. Borisavljevic, K. Boynov, E. Lomonova, and J. Pyrhonen, "Analysis of rotor eddy current losses in slotless high-speed permanent magnet machines," in Power Electronics and Applications (EPE'14-ECCE Europe), 2014 16th European Conference on, Aug 2014, pp. 1-10.

[32] F. Wang, M. Zong, W. Zheng, and E. Guan, "Design features of 
high speed pm machines," in Electrical Machines and Systems, 2003. ICEMS 2003. Sixth International Conference on, vol. 1, Nov 2003, pp. 66-70 vol.1.

[33] B. Gysen, K. Meessen, J. Paulides, and E. Lomonova, "General formulation of the electromagnetic field distribution in machines and devices using fourier analysis," Magnetics, IEEE Transactions on, vol. 46, no. 1, pp. 39-52, Jan 2010.

[34] — "Semi-analytical calculation of the armature reaction in slotted tubular permanent magnet actuators," Magnetics, IEEE Transactions on, vol. 44, no. 11, pp. 3213-3216, Nov 2008.

[35] J. R. Hendershot and T. J. E. Miller, Design of Brushless Permanent-Magnet Machines. Motor Design Books, LLC, 2010.

[36] E. P. Furlani, Permanent Magnet and Electromechanical Devices. Academic Press, 2001.

[37] K. Meessen, B. Gysen, J. Paulides, and E. Lomonova, "Halbach permanent magnet shape selection for slotless tubular actuators," Magnetics, IEEE Transactions on, vol. 44, no. 11, pp. 4305-4308, Nov 2008.

[38] S. R. Holm, "Modelling and optimization of a permanent magnet machine in a flywheel," Ph.D. dissertation, Delft University of Technology, 2003. 